\title{
HABLAR EL ANIMAL LAS PERFORMANCES KAFKIANAS
}

Julieta YELIN Universidad Nacional de Rosario-CONICET julietayelin@conicet.gov.ar

\begin{abstract}
El mundo de Kafka es un Teatro Universal. Para él el hombre se encuentra naturalmente en escena. Y la prueba está en que en el teatro natural de Oklahoma todos son tomados. Resulta imposible comprender los criterios según los cuales se los toma. La aptitud para declamar, que al principio puede parecer decisiva, carece sin embargo de toda importancia. Pero ello puede también ser expresado en los siguientes términos: a los candidatos solo se les pide que reciten el papel de sí mismos. Que ellos puedan ser seriamente lo que dicen ser es cosa que sale del campo de lo posible.

Walter Benjamin, «Franz Kafka. En el décimo aniversario de su muerte».
\end{abstract}

L

as exploraciones teóricas de la crítica literaria, así como las de otras disciplinas dedicadas al análisis de diversas prácticas artísticas, se enfrentan desde hace algunas décadas con el debilitamiento de las perspectivas antropocéntricas, y a las consecuencias que ese deterioro -lento pero implacable - ha tenido sobre los conceptos con los que abordaba, e incluso delineaba, sus objetos de estudio. Esto no es una novedad; y sin embargo, es una constatación que no deja de producir fisuras y desplazamientos en nuestro campo de estudio, abocado cada vez con mayor interés a los desarrollos de la filosofía, la antropología o la biopolítica, de donde procura extraer herramientas críticas para abordar las ficciones contemporáneas, contextualizar sus búsquedas formales, explicar las cegueras y resistencias de algunas de las lecturas más cristalizadas.

Se han ido conformando, así, un corpus conceptual que, a su vez, configura un corpus cultural cada vez más amplio y heterogéneo. Si en un principio el campo de referencia con el que pretendíamos identificar esta crisis ideológica se limitaba a la tradición de la literatura animal -más precisamente, de Franz Kafka a sus herederos consuetudinarios ${ }^{1}-$, con el tiempo se fueron haciendo

\footnotetext{
${ }^{1}$ En nuestras latitudes, por nombrar solo a algunos, Clarice Lispector, João Guimarães Rosa, Felisberto Hernández, Juan José Arreola, Antonio Di Benedetto, Julio Cortázar.
} 
evidentes los rasgos comunes de las experimentaciones recientes en el ámbito de áreas más extensas de la imaginación artística, desde las arañas gigantes de Louise Bougeois o la peletería humana de Nicola Constantino hasta la polémica instalación Bandeira branca de Nuno Ramos, la video performance Sheeps, de Edwina Ashton, o la serie de esculturas taxidérmicas de Jordan Baseman, por dar solo algunos ejemplos ${ }^{2}$.

En el terreno de los estudios literarios, la crítica, además de establecer relaciones transversales con otras artes, propone nuevas lecturas para textos canónicos que no habían sido vinculados anteriormente a estas transformaciones del imaginario ${ }^{3}$, y encuentra en las poéticas del presente interesantes exploraciones de las posibilidades formales y temáticas del pensamiento del animal. Más concretamente: analiza de qué modo, con qué procedimientos, las narraciones operan sobre las variaciones en la percepción de la vida de (y entre) las especies, cuyas fronteras distintivas parecen cada vez más lábiles y permeables (McHugh, 2011: 2). En las ficciones de Osvaldo Lamborghini, César Aira, Mario Levrero, Wilson Bueno o Sergio Ramírez, entre tantos otros escritores que han producido en las últimas décadas en nuestro idioma, el animal exterior y ontologizado es vaciado de sus atributos convencionales y convertido en una herramienta crítica y creadora poderosa. El llamado «giro animal» de la literatura ${ }^{4}$ puede ser entendido, entonces, como un ejercicio de alianza con la animalidad que tiene como efecto la anulación del falso antagonismo entre naturaleza y cultura y el cultivo de una tensión más compleja y dinámica entre cultura y civilización.

En su libro sobre la filosofía animal de Friedrich Nietzsche, Vanessa Lemm analiza la relevancia de esa distinción y apunta que, en el marco de ese sistema de pensamiento, la civilización es entendida como un proyecto de mejoramiento moral y racional del ser humano cuyo principal objetivo es extirpar de él la vida animal. La cultura tiene, frente a ella, una misión de resistencia consistente en mostrar que «la racionalización y la moralización son técnicas de dominación dirigidas contra la animalidad del ser humano». Su función es, por tanto, imponerse frente al dominio de la civilización a través de un trabajo eminentemente creativo, suscitando «formas de vida que no se conviertan en formas de poder sobre la vida, sino que estén ellas mismas plenas y rebosantes de vida» (Lemm, 2010: 38). Este desplazamiento suprime del par opositivo la noción de «naturaleza», origen de todas las estratificaciones y jerarquizaciones de lo viviente propias del pensamiento antropocéntrico, y redefine el concepto de «cultura», incorporando a él una esfera que le había sido negada: aquella orientada a la aceptación de la continuidad existente entre las diversas manifestaciones de la vida.

El trabajo crítico de la cultura atañe tanto a la labor de escritura como a la de lectura, dos actividades ciertamente difíciles de discriminar cuando intentamos conceptualizar qué entendemos por pensamiento literario. Parece necesario, pues, seguir preguntándonos qué caminos puede transitar

\footnotetext{
${ }^{2}$ Sobre la exploración de la animalidad en el arte contemporáneo véanse Baker (2003) y Broglio (2011).

3 Un buen ejemplo es la lectura que hace Jens Andermann del relato «Juan Darién» de Horacio Quiroga (Andermann, 2011).

${ }^{4}$ Para un desarrollo de este tema véase AA. VV. (2011) y Yelin (2011).
} 
la crítica literaria actual para abordar las diversas modalidades en que las creaciones contemporáneas ponen en crisis los fundamentos metafísicos de las perspectivas antropocéntricas. Uno de ellos, y quizás el más atractivo, es el que nos señalan las propias ficciones: el recorrido orgánico, autopoiético - fuera del control de sus creadores- de la obra literaria; como si solo en ellas se pudiera fraguar un pensamiento crítico que no niegue ni esquematice la complejidad del cuestionamiento. La tarea inicial sería, entonces, la caracterización de los procedimientos específicos que las ficciones pueden ofrecerle a la crítica, el estudio detallado de las modalidades que asumen las relaciones entre animalidad, creación y lectura.

Quien avanzó prematura y notablemente en este sentido fue la comparatista norteamericana Margot Norris en su libro Beasts of Modern Imagination: Darwin, Nietzsche, Kafka, Ernst \& Lawrence. El texto es de 1985, es decir que fue publicado diez años después de Kafka. Por una literatura menor, de Gilles Deleuze y Felix Guattari, un antecedente que había procurado ya hacer que la literatura se indagara a sí misma a partir de su propia diferencia para tratar de aprehender aquello que resiste las abstracciones y conceptualizaciones de la filosofía. Ambos textos suponen contribuciones fundamentales para iluminar estos nuevos modos de abordaje posthumanista de los textos literarios, en tanto desde el punto de vista que instituyen es posible identificar discursos y prácticas culturales que producen formas inéditas de relación y distinción entre el animal humano y el resto de los vivientes. Y esas prácticas innovadoras, como es de esperar, transgreden los modelos retóricos de figuración y representación propios de la literatura teriomorfa clásica. Los animales no serán tomados ya como pretexto para pensar lo humano como lo no-animal sino como objeto y medio de una reapropiación de la animalidad negada por y en el hombre.

En los ensayos que componen su libro, Norris enlaza las trayectorias intelectuales de pensadores provenientes de campos del conocimiento y la creación muy diferentes entre sí: Charles Darwin, Friedrich Nietzsche y tres artistas europeos contemporáneos,Franz Kafka, Max Ernst y D. H. Lawrence. Todos comparten el rechazo por aquellas caracterizaciones de lo humano que, ya sea desde discursos religiosos o científicos, sostienen su plenitud respecto del estado de carencia -de razón, de lenguaje, de conciencia- del animal, así como la voluntad de examinar sus propios lenguajes -científicos, filosóficos, narrativos, pictóricos- en busca de una reevaluación de la diferencia ontológica entre hombre y animal. Se emparentan también en el escepticismo respecto de las respuestas filosóficas heredadas y en la reticencia a ofrecer nuevas soluciones bajo la forma de nuevas definiciones opositivas. Por el contrario, estos pensadores que Norris adscribe a la corriente del biocentrismo entienden que la relación hombre-animal debe ser reconsiderada a partir de un discurso ajeno a los binarismos estructuradores que, desde hace siglos, oponen cuerpo y mente, razón e instinto, presencia y ausencia, memoria y olvido, cálculo y espontaneidad, creación e imitación ${ }^{5}$.

\footnotetext{
${ }^{5}$ Estas reconsideraciones tienen, por supuesto, consecuencias éticas y estéticas relevantes. No es mi objetivo aquí analizar sus efectos políticos sobre las formas en que se administra la vida y la muerte en nuestras sociedades, pero quisiera al menos señalar que si el centro del que ha sido desplazado el concepto de «humano» es ocupado por la noción de «vida», queda en evidencia la arbitrariedad de las clasificaciones establecidas y, por tanto, de sus consecuencias concretas sobre los ordenamientos sociales de los cuerpos: el hecho de que existanvidas valiosas y vidas desechables,
} 
La tradición biocéntrica - que no es, como advierte Norris, una genealogía lineal y pacífica, sino más bien una encarnizada discusión en torno de algunos problemas fundamentales- sustituye el estudio retórico de un imaginario animal ligado a realidades ontológicas estables, pasibles de ser representadas por medio de símbolos o alegorías, por el análisis de los modos en que los ensayistas, narradores y/o protagonistas de las ficciones exploran su animalidad en el marco de un universo antropocéntrico. El interés, por tanto, se centra en aquellos pensadores y artistas que crean en tanto animales y no como animales, es decir, imitando a los animales. A partir de una red de lecturas Darwin a través de Nietzsche, Kafka con Darwin y Nietzsche, Lawrence con Kafka-, va tomando forma en el discurso de Norris una vertiente de pensamiento que es, ante todo, un ejercicio de negatividad, de resistencia a los métodos y recursos del arte y la crítica humanista; una crítica a la abstracción, sobrevaloración y desplazamiento de la naturaleza, a la confianza en el realismo o en símbolos que evocan realidades profundas, a la apelación a la figura del autor como otorgador de sentido y a la del lector como decodificador. Tal resistencia tiene lugar gracias al «uso diestro de la crítica, que invoca la representación solo con el fin de desmantelarla». Por eso Norris recurre a la metáfora nietzscheana de la filosofía del martillo: «un ejercicio a un tiempo de poder y de agresión, y la destrucción de los ídolos de la cultura designificándolos y desmistificándolos (es decir, usando el martillo para hacer resonar su centro vacío)» ${ }^{6}(16)$.

Pero no se trata solo de un trabajo de negatividad. El desplazamiento del punto de vista ha dado lugar también a formas afirmativas de considerar la relación entre el animal humano y los demás vivientes, a la valoración del cuerpo y su efusión de poder, con la apelación a una «epistemología instintiva» y a la «celebración de la experiencia no mediada» (Norris, 1986: 3). Estos rasgos son perceptibles en el campo de las artes visuales, donde desde los años setenta del siglo pasado proliferan experiencias que escenifican relaciones materiales entre el cuerpo físico del artista y el de los animales, sin atenuaciones simbólicas o estetizaciones, desnaturalizando la violencia a la que son sometidas diariamente enormes masas de seres vivos en nuestras sociedades ${ }^{7}$. El arte biocéntrico cuestiona así la reducción que implica la consideración de los aspectos exclusivamente humanos de la cultura, la concepción del universo cultural como producto exclusivo del hombre, único dador de significado, y aboga por la constitución de lo que Ron Broglio caracteriza como una «fenomenología animal»o, más exactamente, de fenomenologías animales que se ocupen de los encuentros entre el mundo humano y el mundo animal, de las zonas de contacto.

\footnotetext{
sometidas al rigor de lo que se ha denominado tanatopolítica. Tales reordenamientos tienen interés para nuestro trabajo en tanto ponen de manifiesto la arbitrariedad de las fronteras que el biocentrismo discute a través del ejercicio crítico y creativo; es decir, muestran que la oposición humano/animal es eminentemente política y, por tanto, objeto de controversias y disputas.

${ }^{6}$ En éste y en todos los casos en que citamos el libro de Norris, la traducción es nuestra.

${ }^{7}$ En su libro Artist / Animal, Steve Baker estudia algunas performances animales en las artes plásticas contemporáneas -en las que incluso se llegan a utilizar animales reales-, subrayando su preferencia por la materialidad de los cuerpos y la experiencia directa e inmediata en detrimento de la descripción o la representación. En la introducción del libro, Baker analiza RatPiece (1976) performance en la que Kim Jones incineró ratas vivas, y Helena (2000) de Marco Evaristti, instalación que ofrecía al público la posibilidad de eliminar peces que nadaban dentro de licuadoras eléctricas.
} 
La crítica al antropocentrismo no puede, por tanto, tener lugar en el marco de prácticas de negación del otro-no-humano como vía de autoafirmación, es decir, no puede encauzarse en los protocolos del arte tradicional; debería más bien buscar mecanismos que pongan en el centro de la escena esas formas que Giorgi y Rodríguez llaman «excesos de vida» ${ }^{8}$, virtualidades listas para ser actualizadas una y otra vez, para mutar indefinidamente. Y tendría que intentar hacerlo sin ofrecer un relato, sin apropiárselas; negando la autoridad como forma de fijación del sentido, quebrando la representación como garantía y rechazando la interpretación como reaseguro. La experimentación genérica y retórica sería, pues, condición de posibilidad para que la literatura animal se convierta en un campo de experimentaciones en torno al bíos, en una apuesta por una deshumanización de la imaginación estética.

Los ensayos de Norris, y muy en especial aquellos que dedica a textos ficcionales, apuntan lúcidamente en esa dirección, analizando algunas de las soluciones técnicas que los artistas han aportado al problema de la literaturización de universos deshumanizados. Esas soluciones pasan fundamentalmente por la elaboración de lo que denomina «modos antirrepresentacionales»; entre ellos, la representación de la violencia hacia la representación, la de-significación de la figura del animal y la experimentación retórica con el punto de vista animal. Como veremos a continuación, estos tres procedimientos son solidarios y sobre ellos se podría decir que se cimienta una buena parte de la literatura animal postkafkiana. Es decir, aquella que se ha dejado arrastrar y transformar por la crisis del imaginario animal.

\section{Antirrepresentaciones}

¿Cómo entender la formulación paradójica «representar la violencia hacia la representación»? Sabemos que las ficciones que más violentamente atentaron contra la superioridad ontológica del hombre son aquellas que exhibieron la imposibilidad de concebir una imagen acabada del animal. En los relatos teriomorfos de Kafka ese efectose consigue por medio de la creación de lo que Nietzsche ha llamado metáforas intuitivas: un trabajo deconstructivo que deshace y disuelve el paradigma de verdad del pensamiento metafísico permitiendo captar la manifestación de una alteridad, de una experiencia singular imposible de expresar por medio del lenguaje conceptual.

La experiencia de todos los narradores animales de Kafka es, como apunta Norris, la de la indiferenciación. En «Josefina la cantora o el pueblo de los ratones» la protagonista es una roedora que, aunque está convencida de sus excepcionales dotes artísticas, no logra probar la diferencia de su canto -es decir, su propia diferencia- respecto del chillido de los demás ratones ${ }^{9}$. Tampoco lo consigue el ratón que se hace cargo de la narración y el resultado es que, en lugar de ser contada, «la

\footnotetext{
${ }^{8}$ «Siempre hay más de una vida, más de un mundo posible; la vida está de más respecto a la totalidad de lo dado, no como un exceso que se disipa o se deja de lado, sino como un potencial de devenir que, como un sueño, espera ser realizado» (Giorgi y Rodríguez, 2007: 23).

${ }^{9}$ Oscar Caeiro (1976) recuerda que el relato fue publicado por primera vez como «Josefina, la cantora». El título dejaba en duda el carácter verdaderamente animal de los personajes, pues el verbo mediante el cual se designa el peculiar sonido proferido por las ratas -leitmotiv de la historia- es en alemán «pfeifen», que significa tanto el chillar de ciertos animales como la acción humana de silbar.
} 
historia de Josefina se inscribe negativamente en el fracaso de la narración» (120). El relato niega rigurosamente - con la tenacidad argumentativa propia del discurso kafkiano- todo lo que afirma, de modo que Josefina acaba siendo a un tiempo artista y no-artista, única y ordinaria, singular y plural, humana y animal. Al inicio de su relato Kafka utiliza el procedimiento humanista de la antropomorfización (un ratón artista), pero luego lo desactiva por completo. Un truco que excede el mero efecto antimimético: no es que Josefina sea imposible de representar sino que la representación, una vez conseguida, se desvanece. El narrador elimina la distinción entre canto y ruido mediante la puesta en cuestión del carácter veraz de la percepción; para constituirse como canto, los sonidos de Josefina deberían exhibir algunos rasgos distintivos que permitieran contrastarlos con el chillido de los ratones, pero ¿quién podría decir si esos sonidos tienen o no sentido? O, mejor: ¿dónde está la línea que separa el sentido del no sentido? Kafka llega a esta pregunta mediante un juego de negaciones. Dice el narrador ratón al comienzo del relato: «Quien no la haya oído cantar no conoce el poder del canto. No hay nadie a quien su canto no arrebate» (Kafka, 2004: 276).Solo bien avanzado el relato, cuando comenzamos a preguntarnos si Josefina es realmente una cantante, comprendemos la estructura litótica de las afirmaciones. «La doble negación, la negación de lo contrario, sugiere la posibilidad de que no haya habido nada en primer lugar -ni canción ni cantante- y de que las afirmaciones refieran solo a un vacío o a una huella» (Norris, 1985: 120-121).

Ése es el movimiento de representación de la violencia hacia la representación, que tiene como efecto la de-significación de la figura del animal, y que es reconocible también en los narradores animales del «Informe para una academia», «Investigaciones de un perro», «Chacales y árabes»o «La madriguera». En todos estos relatos Kafka problematiza la relación entre lo particular y lo universal, que es en rigor la tensión desplegada en todas aquellas narraciones de animales que no ceden ante la tentación de las correspondencias simbólicas. Para que un animal no sea ni la especie es decir, para continuar con Josefina, todos los ratones- ni el individuo - un ratón singular, antropomorfizado-, debe sostener la ambigüedad, estar entre ambas categorías, mantenerse en tránsito -como Pedro el Rojo-, o ir y venir de una a otra -como Kalmus, de las «Investigaciones...». Y esa de-significación se efectúa mediante la experimentación con el punto de vista animal, al que los artistas, si no quieren caer en la trampa de la psicologización, pueden acceder solo haciéndose cargo de una actuación. De una performance animal.

Veamos, entonces, qué mecanismos formales activa este giro genérico.

En el prólogo que escribió para una edición española de La transformación y otros relatos, César Aira argumenta que el estilo narrativo de Kafka se caracteriza por una deriva de la razón a la sinrazón: hay un intelecto que recorre los hechos paso a paso, ordenadamente y sin interrupciones, pero que es subrepticiamente minado por la emergencia de la rareza, de la anomalía de su singularidad, produciéndose así un tránsito de lo general a lo particular: «El razonamiento, por serlo, participa del consenso general. Pero mantenido durante el tiempo suficiente por un individuo, aun cuando no suceda nada especial, se tiñe de la clase de locura propia de la soledad. Entonces, cuando 
aparece el "error", empieza a justificarse la existencia de un discurso nuevo en el mundo». Y ese discurso nuevo podría ser aún más revelador, según Aira, si brotase de la boca de un animal: «la honestidad derivada de su inocencia, la ignorancia de las trampas y engaños del discurso humano, lo llevarían antes a la sinrazón constitutiva del individuo» (2003: 17). El animal kafkiano es, concluye, una hipótesis del discurso.

Performativizar, hablar el animal, puede ser para el escritor un modo de tantear zonas negadas de su propia existencia; actualizar la hipótesis discursiva, ponerla en juego y ver qué da de sí. Es precisamente lo que ensaya una y otra vez Kafka cuando en sus últimos relatos de animales, esos monólogos que coquetean continuamente con el delirio, procura dar respuesta a la pregunta ¿qué -y cómo- es ser un animal? No solo cómo perciben los animales el mundo que los rodea -preocupación presente en las investigaciones de sus contemporáneos, el filósofo Martin Heidegger y el zoólogo Jacob von Uexküll-, sino también cómo haría el animal, si pudiera, para narrar esa experiencia. Enr en «Sloughing the Human», un ensayo sobre performances de la animalidad en las artes visuales contemporáneas, Steve Baker dice -en consonancia con Norris- que la respuesta artística ya no encuentra un cauce en la imitación ni en la representación. Solo parece viable una propuesta que extienda las posibilidades formales de las diversas prácticas ampliando, al mismo tiempo, el horizonte del pensamiento crítico; haciendo que éste apunte a la búsqueda del animal y la animalidad sin reducciones ni violencias, sin retóricas de la traducción, sin conversión de la extrañeza en familiaridad.

¿Qué es ser un animal? ¿Qué hace falta, qué es lo apropiado para sugerir o actuar en relación con el otro-no-humano? No es una cuestión de extravagancia sino de sobriedad -se trata de juzgar cómo dar un paso a un lado de lo humano, señalar al otro, dar cuenta del animal, y por tanto registrar ese estado «experimental» de suspensión de la identidad que ha sido tan concisa y controvertidamente definido como devenir-animal (Baker 2003: 147) ${ }^{10}$.

Si la literatura de Kafka participa aún hoy activamente de los debates culturales en torno del estatuto del animal en nuestras sociedades es porque ha dado ese paso a un costado con una radicalidad inédita. Un desplazamiento estético, pero también filosófico y político que corre el eje de la discusión sobre el «discurso de la especie» (Wolfe 2003) del plano metafísico y narrativo -hablar del animal- al performático -hablar el animal-. Los parlamentos enloquecidos de los animales kafkianos muestran que el lenguaje, deslindado de la metafísica subjetiva, puede efectivamente animalizarse, y que esa transformación afecta nuestra percepción de lo viviente no-humano. Estas performances deberían considerarse en un sentido ritual o antropológico, es decir, como prácticas que instauran una dialéctica de flujo, «un movimiento espontáneo en el que acción y conciencia son uno ${ }^{11}$ (Schechner, 2000: 16), y en el que arte y vida se fusionan, pierden consistencia y producen pensamiento de lo que para la filosofía, en tanto sistema de categorías estables, resulta impensable. Un ritual entendido como acontecimiento en tiempo presente, espacio limítrofe donde es posible el

\footnotetext{
${ }^{10}$ La traducción es nuestra.

${ }^{11}$ Schechner cita una intervención oral del antropólogo Victor Turner, de 1980.
} 
cambio, la transición entre diversos estados o, para usar términos kafkianos: metamorfosis, transformaciones.

Lamentablemente no hay, hasta donde sabemos, estudios que ahonden en la relación de la escritura de Kafka con el teatro, quizás una fuente fundamental de sus performances animales. No es nuestro objetivo hacerlo aquí, pero sí nos gustaría al menos trazar un breve recorrido de lectura por algunos relatos para exponer la relevancia de ese vínculo en el programa de escritura kafkiano, no sólo a nivel temático sino también, y sobre todo, en la constitución de una poética en la que la acción de los personajes es presentada como actuación. Y en lo que respecta a nuestro campo más específico de intereses: esbozar la hipótesis de que la obra de Kafka pone en crisis la idea misma de humanidad desnudando lo grotesco de su pose, la poca estabilidad de la imagen que permite a los hombres sostener y justificar su jerarquía como especie.

El interés de Kafka por el género dramático se habría iniciado en 1911, año en que una compañía popular yídish se instaló durante varios meses en un café de Praga. Kafka asistió regularmente a las funciones y se hizo muy amigo deYitzchak Lowy, un actor polaco con quien mantuvo largas conversaciones sobre aspectos específicos de dramaturgia e interpretación que se plasmaron en numerosas reflexiones de los Diarios. En el tercer cuaderno, por ejemplo, es frecuente la narración detallada del argumento de las obras a las que asistía ${ }^{12}$ y de las sensaciones que le despertaban las representaciones de la compañía itinerante ${ }^{13}$, a veces transmutadas en sus sueños ${ }^{14}$. Kafka dedica siempre una atención especial a la gestualidad de los actores, de la que saca valiosas conclusiones sobre el trabajo actoral y su relación con el efecto de verosimilitud. En ocasiones incorpora esas observaciones a otras descripciones cotidianas, alimentando la idea de que el teatro no se restringe al espacio escénico, sino que es más bien una lente para observar eso que Walter Benjamin (1971), en sus reflexiones sobre América, llama «Teatro Universal»: un mundo en el que todos intentan representar el papel de sí mismos.

La empleada de la oficina de Karl me recordó a la actriz que hacía el papel de ManetteSalomon en el Odéon de París, hace un año y medio. Al menos cuando estaba sentada. Unos senos suaves, más anchos que altos, ceñidos por una tela de lana. Una cara ancha hasta la boca, pero que luego se estrecha rápidamente. Rizos descuidados, naturales, en un peinado liso. Ardor y calma en un cuerpo fuerte. El recuerdo se reforzó, como noto ahora, por el hecho de que trabajaba de firme (en la máquina de escribir volaban las teclas -sistema Oliver- como en los viejos tiempos la agujas de hacer punto), también iba y venía de un lado para otro, pero en media hora apenas dijo unas pocas palabras, como si llevase dentro a ManetteSalomon (Kafka, 2000: 198-199).

\footnotetext{
12 «Una joven viuda se casa con un viejo que tiene cuatro hijos y enseguida mete en el matrimonio a su amante, WladimirWorobeitschik. Entre los dos arruinan a toda la familia [...]» (Kafka, 2000: 171).

13 «Qué lastimados me parecieron los actores después de la función, cómo temí tocarlos ligeramente con una palabra mía. Cómo preferí irme rápidamente, como si estuviera enfadado y descontento, porque me resultaba tan imposible expresar la verdad de mi impresión» (Kafka, 2000: 175).

14 «19.XI 1911, domingo. Sueño: En el teatro. Representación de Das waiteland [El vasto país] de Schnitzler, adaptado por Utitz. Estoy sentado delante de todo, en un banco, creo estar sentado en el primero, hasta que acaba resultando que es el segundo. El respaldo del banco está vuelto hacia el escenario, de modo que se puede ver cómodamente la sala, pero para ver el escenario hay que darse la vuelta. El autor está por allí cerca, no puedo callarme mi juicio desfavorable sobre su obra, que por lo visto ya conozco, pero a cambio añado que el tercer acto, según dicen, es gracioso. Con ese "según dicen" doy a entender a mi vez que, si se habla de sus pasajes buenos, no conozco la obra y tengo que fiarme de lo que he oído; vuelvo a repetir la observación, no solo para mí, pero losdemás no la escuchan» (Kafka,2000: 211).
} 
En el discurrir de esas reflexiones que transitan con total naturalidad de la vida cotidiana a la escena teatral, Kafka desliza una pregunta medular acerca del efecto derealidad en el teatro: ¿en qué consiste una mala actuación? Y responde que la esencia del mal actor no consiste, como podría suponerse, en que su interpretación sea débil sino, por el contrario, en que no respete los límites de la actuación e imite con demasiada intensidad (Kafka, 2000: 265-266). Sobriedad mejor que extravagancia, para retomar las palabras de Baker.

Por un lado, entonces, el teatro será para Kafka una fuente de pensamiento sobre la relación vida-literatura; por otro -y esto es lo más relevante para la cuestión que nos interesa analizar-, el fenómeno dramático constituirá un espacio privilegiado de reflexión sobre la materia de la que están hechos sus personajes; sobre la forma en que éstos transmutan su experiencia en una actuación. En «Un artista del trapecio»y «Un artista del hambre» ambos protagonistas ensayarán animalizaciones, e inversamente, como veremos a continuación, en el «Informe para una academia» el narrador realizará una performance de la humanidad. Y la clave estará en que la imitación sistemáticamente fracase: los hombres y animales kafkianos no pueden ser sujeto ni objeto de imitación porque comparten una vida secreta que emerge frustrando tanto la distinción como el efecto mimético; una vida que permanece oculta y a la vez presente en cada intento de negarla o invisibilizarla. Y esos ejercicios son siempre, como muestran una y otra vez las narraciones, de una violencia devastadora.

El argumento del «Informe para una academia» es aparentemente sencillo: Pedro el Rojo, un ex mono, cuenta, a pedido de un grupo de científicos, su dolorosa historia de cautiverio, metamorfosis y liberación. Pero el informe se inicia, como suele suceder en muchos de los relatos de Kafka, con una advertencia sobre la imposibilidad de la tarea encomendada.

Eminentes señores de la Academia:

Ustedes me han hecho el honor de pedirme que presente a la Academia un informe sobre mi simiesca vida anterior. En este sentido, lamentablemente, no puedo satisfacer la petición. Casi cinco años me separan de la simiedad; un tiempo quizá corto si se mide con el almanaque, pero interminablemente largo para cruzarlo al galope, como lo he hecho yo, acompañado en algunos tramos por personas eminentes, consejos, aprobación y música de orquesta, pero en el fondo solo, ya que toda compañía, para no salirse del marco, se mantiene lejos, del otro lado de la barrera (Kafka, 2004: 237).

Esa barrera que separa a Pedro a un tiempo del pasado animal y del futuro humano es la causa de su enajenación y, por tanto, el motor principal del relato, que no narrará, en definitiva, más que la tentativa malograda de acceder a una historia que al narrador no le pertenece. Por eso las primeras peripecias son contadas a través de un recuerdo prestado; dice Pedro: «Soy originario de la Costa de Oro. Sobre cómo me cazaron debo remitirme a informes de otras personas» (Kafka, 2004: 239). Enseguida explica cómo fue herido por dos balazos - uno en la mejilla y otro debajo de la cadera, que lo dejó rengo- en una expedición de caza nocturna de la firma Hagenbeck. Después de aquellos disparos - continúa - se despertó dentro de una jaula en un barco de la compañía, y es solo a partir de ese momento que comienza a discurrir de modo intermitente su propio recuerdo.

Con el cautiverio se inicia lo que Nietzsche caracteriza como el proceso decadente de la civilización; esto es, una labor de domesticación guiada por el deseo de encorsetar la vida mediante 
imposiciones. Práctica que confronta en la filosofía nietzscheana con el «cultivo» entendido como proceso de liberación del animal humano a través de la cultura, fuerza transformadora, plural, creadora $^{15}$. Desde este punto de vista, entonces, la civilización solo es posible mediantela instauración de una ficción ontológica. «Aquello que en la competencia contra los animales trajo aparejada la victoria humana produjo al mismo tiempo el desarrollo arduo y peligroso, como el de una enfermedad, del ser humano: el ser humano es el animal que aún no ha sido confirmado» (Lemm, 2010: 50) ${ }^{16}$. La memoria humana se construye, así, sobre la sepultura del animal que se está haciendo y que retorna invariablemente, produciendo fisuras, blancos, zonas de ceguera.

Todas esas luchas y solapamientos entre memoria y olvido son iluminados con deslumbrante lucidez en el «Informe» kafkiano. Solo una vez que se ha consumado el secuestro e iniciado el proceso de domesticación, comienza a tomar forma en el discurso del narrador algo semejante a la memoria humana. Y esa memoria trae consigo el sufrimiento. Pedro cuenta con detalle los métodos brutales que se utilizaron para su humanización: encerrado en una jaula, agachado, tembloroso y en silencio, el ex-mono se encuentra, por primera vez en su vida, sin una salida. « $i$ Yo había tenido hasta entonces tantas salidas!... ¡y ahora ya ninguna! Estaba encallado. Si me hubiesen clavado, mi libertad de movimientos no habría disminuido por eso. [...] No tenía ninguna salida, pero tenía que encontrar alguna porque sin ella no podía vivir» (Kafka, 2004: 241). Es entonces cuando decide dejar la realidad simiesca para abrazar la existencia humana, emprendiendo un viaje sin punto de llegada ni posibilidad de retorno al origen -si al principio creía posible hacer el camino inverso hacia la animalidad «recorriendo todo el arco que forma el cielo sobre la tierra», con el tiempo esa vía se va «estrechando y achatando» a medida que continúa la «forzada evolución hacia adelante» (238)-. La parodia de la teoría darwinista es coherente con la interpretación nietzscheana sobre la inexistencia de un origen natural recuperable: la naturaleza no es un edén perdido y, por tanto, un retorno a ella, como ambicionaban los románticos, es imposible. Jamás ha existido algo así como una inhumanidad o una pre-humanidad natural.

Por eso la creación literaria de un punto de vista animal como el figurado por Kafka en el relato de Pedro el Rojo no supone un abandono de la animalidad en busca de la humanidad deseada sino más bien la imagen del momento en que un hablante se descubre a sí mismocomo realidad heterogénea; o, para volver a una metáfora darwiniana, como palimpsesto: el hombre no es ya el prototipo de una forma ideal en su unidad, identidad, integridad y perfección; es una criatura híbrida e incluso monstruosa que contiene pequeños fragmentos y rastros de otros animales, aspectos masculinos y femeninos, destellos instintivos primitivos cubiertos por un comportamiento civilizado. Es, dice Norris, siguiendo el razonamiento evolucionista, como si esas huellas animales «estuviesen escritas en una tinta invisible, pero listas en cualquier momento para desenvolverse bajo ciertas condiciones» ${ }^{17}(1985: 40)$.

\footnotetext{
15 «En lugar de imponer una forma universal sobre la vida, la cultura como cultivo está orientada hacia la pluralización de formas de vida intrínsecamente singulares que no pueden ser reducidas las unas a las otras» (Lemm, 2010: 41).

${ }^{16}$ Lemm cita a Nietzsche (SämtlicheWerke in 15 Bänden. KritischeStudienausgabe 11:25 [428]).

${ }^{17}$ Norris cita aquí un fragmento de La variación de los animales y las plantas bajo domesticación de Charles Darwin.
} 
Este modo de entender la animalidad olvidada resulta en un sinceramiento respecto de la imposibilidad de crear un punto de vista en el que lo humano y lo animal no se contaminen mutuamente. $\mathrm{Y}$ en los textos kafkianos esa aceptación tiene la particularidad añadida de ser escenificada por medio de un desdoblamiento dramático: al oír el pensamiento o los monólogos delirantes de las bestias parlantes el lector percibe cabalmente que se trata de una actuación. No de una falacia ni de una importación, sino de una actuación en su sentido más lato, espectacular.

Gregorio, el protagonista de La metamorfosis, actúa como una cucaracha pese a conservar muchas de sus facultades humanas; Kalmus, el narrador de «Investigaciones de un perro», procura comportarse como el resto de sus congéneres aunque no entienda muy bien cuál es el modelo de conducta al que debe atenerse; Josefina sostiene obstinadamente que no es una ratona del montón sino una artista extraordinaria, un espécimen único. Y en el «Informe para una academia» la humanidad del protagonista no será sino una performance que oculta el olvido del pasado animal como condición de posibilidad de su memoria histórica; es decir, de su acceso a la civilización. Para imitar a los hombres, Pedro el Rojo se ve obligado a rechazar el retorno incesante de lo reprimido por ejemplo, al percibir el extravío de la pequeña chimpancé con la que convive: «Durante el día no quiero verla; es que tiene en la mirada la locura del animal amaestrado, desequilibrado; de esto solo yo me doy cuenta y es algo que no puedo soportar» (Kafka, 2004: 249). La humanidad teatralizada denuncia la fragilidad de la civilización con la que el hombre garantiza su excepcionalidad, su precario triunfo frente a la amenaza latente del animal. Así las cosas, parece decir Kafka, solo nos queda actuar, ponernos el mejor traje para transitar la oscuridad. «Hay una excelente expresión alemana: "internarse en la espesura". Eso fue lo que hice: me interné en la espesura. No tenía otro camino, siempre partiendo de la base de que no se podía elegir la libertad» (248-249).

En la espesura silenciosa de las performances kafkianas laten una filosofía y una fenomenología animal que podrían, ciertamente, guiar nuestras prácticas de lectura hacia lugares no conocidos. Solo es necesario que se extinga, al menos por un instante, la luz cegadora del discurso antropocéntrico.

\section{Bibliografía}

AA. VV. (2011): «El giro animal», Pensamiento de los confines, 27, pp. 81-156.

AIRA, César (2003): «Prólogo», en Franz Kafka,La transformación y otros relatos.Barcelona, Círculo de Lectores, pp. 9-26.

ANDERmann, Jens (2011): «Tesis sobre la metamorfosis», Boletín del Centro de Estudios de Teoría

y Crítica Literaria, 16, en http://www.celarg.org/int/arch_publi/andermann_animalidad.pdf.

BAKER, Steve (2003): «Sloughing the Human», en Cary Wolfe, ed., Zoontologies. The Question of the Animal.Minneapolis, University of Minnesota Press, pp. 147-164.

- (2013): Artist / Animal. Minneapolis, University of Minnesota Press.

Benjamin, Walter (1971): «Franz Kafka. En el décimo aniversario de su muerte», en Angelus Novus.Buenos Aires, Sur, pp. 91-125. 
Broglio, Ron (2011): Surface Encounters. Thinking With Animals and Art. Minneapolis, University of Minnesota Press.

CAEIRO, Oscar (1976): «Prólogo», en Franz Kafka, Un informe para una academia y Josefina, la cantora o el pueblo de los ratones. Buenos Aires, Editorial y Librería Goncourt, pp. 7-17.

GiorgI, Gabriel, y RodríGuEZ, Fermín, comps. (2007): Ensayos sobre biopolítica. Excesos de vida, Buenos Aires, Paidós.

KAFKA, Franz (2000): Diarios. Carta al padre. Barcelona, Galaxia Gutemberg. Círculo de Lectores.

- (2004): Cuentos completos. Madrid, Losada.

LEMM, Vanessa (2010): La filosofía animal de Nietzsche. Cultura, política y animalidad del ser humano. Santiago de Chile, Universidad Diego Portales.

McHugh, Susan (2011): «Introduction. Animal Narratives and Social Agency», enAnimal Stories. Narrating Across Species Lines. Minneapolis, University of Minnesota Press, pp. 1-23

NIETZSCHE, Friedrich (1999):Sobre la utilidad y el perjuicio de la historia para la vida [II Intempestiva]. Trad. Germán Cano.Madrid,Biblioteca Nueva.

NORRIS, Margot (1985): Beasts of Modern Imagination. Darwin, Nietzsche, Kafka, Ernst \& Lawrence. Baltimore and London, The Johns Hopkins University Press.

SCHECHNER, Richard (2000): Performance. Teoría y prácticas interculturales. Buenos Aires, Libros del Rojas.

Wolfe, Cary (2003): Animal Rites. American Culture, the Discourse of Species and Posthumanist Theory. Chicago, University of Chicago Press.

YeLIN, Julieta (2011): «El giro animal. Huellas kafkianas en la escritura de César Aira y Wilson Bueno», Boletín del Centro de Estudios de Teoría y Crítica Literaria, 16, en http://www. celarg.org/int/arch_publi/yelin_animalidad.pdf. 